\title{
Economic Thermal Power Dispatch with Emission Constraint and Valve Point Effect loading using Improved Tabu Search Algorithm
}

\author{
K.Senthil \\ Department of Electrical \& Electronics Engineering \\ St.Joseph College of Engineering \& Technology \\ Dar Es Salaam \\ Tanzania
}

\author{
K.Manikandan \\ Department of Electrical \& Electronics Engineering \\ S.R.M University \\ Chennai \\ India
}

\begin{abstract}
Economic load dispatch (ELD) is an important optimization task in power system. It is the process of allocating generation among the committed units such that the constraints imposed are satisfied and the energy requirements are minimized. There are three criteria in solving the economic load dispatch problem. They are minimizing the total generator operating cost, total emission cost and scheduling the generator units. Each of the above criteria is used with the following constraints such as power balance constraints, generator limit constraints, valve point coefficients and emission constraints. In this paper the Improved Tabu Search (ITS) solution to economic dispatch problem is very useful when addressing heavily constrained optimization problem in terms of solution accuracy. Results obtained from this technique clearly demonstrate that the algorithm is more efficient in terms of number of evolution to reach the global optimum point. The result also shows that the solution method is practical and valid for real time applications. In this paper an Improved Tabu Search (ITS) algorithm solves economic load dispatch (ELD) power system problem of three generator system, six generator system with emission constraints and thirteen generator system with valve point effect loading.. The Improved Tabu Search (ITS) algorithm was used to check the validity, quality of the solution and the results are tabulated. The validity and quality of the solution obtained using proposed Improved Tabu Search (ITS) based economic load dispatch method are checked and compared with Hopfield Neural Network (HNN), Genetic Algorithm (GA), Tabu Search Algorithm (TSA) and Distributed Tabu Search Algorithm (DTSA).
\end{abstract}

\section{Keywords}

Economic dispatch, valve-point effect, Emission constraint, Improved Tabu search.

\section{INTRODUCTION}

Energy management has to perform more complicated and timely system control function to operate a large power system reliably an efficiently. In electric power system operation, the objective is to achieve the most economical generation policy that could supply the local demands without violating constraints. Thermal stations, during power production, burn fossil fuels that generate toxic gases in their effluent and these become a source of pollution for the environment. Lack of planning while generating power puts the economical aspect in jeopardy. Within a plant, however, there are no transmission loss units; rather pollution exists due to emission. The cost minimum condition corresponds to minimum cost with considerable amount of emission. Similarly, the emission minimum condition produces minimum emission with higher deviation from minimum cost. These two conditions cannot be implemented simultaneously. Hence, the feasible optimum corresponds to a small deviation in cost with an allowable tolerance in emission taking into account emission constraints and this has been termed emission constrained economic dispatch (ECED).

Economic dispatch is one of the most important problems to be solved in the operation of power system. The traditional method such as lambda iteration method, the base point, the participation factors method and gradient method are well known for the economic thermal dispatch of generators. All the methods as well known for the economic dispatch problem as a convex optimization problem and it assumes the whole of the unit operating limit $\left(\mathrm{P}_{\min }\right)$ and the maximum generation limit $\left(\mathrm{P}_{\max }\right)$ is available for operation.

This paper work deals with the economic scheduling problem namely the economic thermal power dispatch. In seeking the solution for the economic dispatch problem (EDP) the main aim is to operate a power system in such a way to supply all the loads at the minimum cost. The solution technique which is applied to the economic load dispatch is Improved Tabu search (ITS) method. The basic idea of the ITS approach is to use adaptive memory structures and associated strategies to explore the search space of feasible solutions by means of a sequence of moves. The simplest version of this method only makes use of its short term memory process. The elements of the more from the current solution, to its selected neighbour are partially or completely recorded in the Tabu List to forbid reversal of the replacement in future iterations. Without his assurance, the search would cycle between the first encountered local optimum and its neighbour. Considerable success is achieved for short term memory, which makes use of frequency information and more advanced principles. This influences the effective implementation of Improved Tabu Search. A good deal of literature is available pertaining to the topic of research considered in this thesis. The traditional method of solving economic dispatch problems such as lambda-iteration and gradient method requires the unit input-output curves of generators. However, these curves do not increase monotonically due to prohibited operating zones. Hence, the traditional dispatch algorithms cannot be directly used to optimize such non-linear cost function. Wong suggested the Evolutionary programming 
based algorithm for environmentally constrained economic dispatch [1] to solve the highly non linear economic dispatch problem without restrictions on the shape of the fuel cost functions. These applications involved a large number of iterations and susceptible to the related control parameters. Park analyzed the adaptive learning approach in the Hopfield Neural Network [2] using the slope adjustment and has adjustment methods for application to economic load dispatch. These methods reduce transient period drastically. The adaptive learning in both methods gives better response compared to fixed learning rate. The bias adjustment method gives good response especially in the beginning of the process. Both methods reduced the number of iterations to one half of the traditional Hopfield neural network. When the momentum is introduced to all methods in either input or gain, the number of iterations and the computation time are reduced in the order of magnitude. Sewothul and Rughooputh have studied genetic algorithm for economic dispatch with valve point effect [3] develops four genetic algorithms: simple genetic algorithm, Simple genetic algorithm with generation-apart elitism, Simple genetic algorithm with atavism and atavistic genetic algorithm for non monotonically increasing cost functions.

Basu analyzed the interactive fuzzy satisfying-based simulated annealing technique [4] for economic emission load dispatch with non smooth fuel cost and emission level functions treats economic and emission as competing objectives for optimal dispatch, which requires some form of conflict resolution to arrive at a solution. Assuming that the decision maker has imprecise or fuzzy goals for each of the objective functions, the multiobjective problem is transformed into a minimax problem, which is then handled by the simulated annealing technique. Khamsawang and Pothiya have suggested a novel method on simple Tabu search algorithm (TSA) to solve economic dispatch (ED) problem for thermal power plants, which we call Distributed Tabu Search algorithm (DTSA) [5]. It consists of thirteen generating units with valve point effect fuel functions. Basu analyzed the dynamic economic emission dispatch [6] is an extension of the conventional economic emission dispatch problem that takes into consideration the limits on the ramp rate of the generating units. The multiobjective problem is converted into a single-objective optimization by goalattainment method which is then handled by particle swarm optimization method. Muralidharan and Srikrishna have studied dynamic programming recursive approach for the Emission constrained economic dispatch [7] presented a multiobjective and multi stage decision making problem has been solved analytically without the familiar lambda iteration method. The optimization algorithm has been developed with a sequential dynamic programming model. The salient feature of this technique is that all the former conventional procedures have been avoided completely. Whei-Min Lin and Fu-Sheng Cheng implemented an Improved Tabu Search Algorithm [8] for economic dispatch with non continuous and non smooth cost functions. Modified Tabu Search generates new population from one candidate and usually converges to local optimum very quickly, for ITS vectors with fitness score good enough would be used as candidates to create new solutions regardless of Tabu restrictions. The theory of tabu Search has been well developed an Improved Tabu Search Algorithm (ITS) to make Tabu Search more practicable in real valued systems.

\section{PROBLEM FORMULATION}

The objective of solving the economic dispatch problem in electric power system is to determine the generation levels for all on-line units which minimize the total fuel cost and minimizing the emission level of the system, while satisfying a set of constraints. It can be formulated as follows:

The economic dispatch problem can be modelled by

$$
\text { Minimize FT }=\sum_{i \varepsilon \Omega} F_{i}\left(P_{i}\right) \quad \$ / \mathrm{hr}
$$

Where

FT is the total fuel cost

$F_{i}\left(P_{i}\right)$ is the fuel cost of generating unit i

\subsection{Fuel Cost Function}

The fuel cost function of a generating unit is usually described by a quadratic function of power output $\mathrm{P} i$ as:

$$
F_{i}\left(P_{i}\right)=\mathrm{a}_{\mathrm{i}} \mathrm{P}_{\mathrm{i}}{ }^{2}+\mathrm{b}_{\mathrm{i}} \mathrm{P}_{\mathrm{i}}+\mathrm{c}_{\mathrm{i}} \quad \$ / \mathrm{hr}
$$

Where

$\mathrm{a}_{\mathrm{i}}, \mathrm{b}_{\mathrm{i}}$ and $\mathrm{c}_{\mathrm{i}}$ are the cost co-efficient of unit $\mathrm{i}$

\subsection{Valve Point Effect Loading}

To model the cost function of generators in a more practical manner, valve point effect is considered where the input-output curve is not linear but consists of ripples as a result of the sharp increase in losses due to the wire drawing effects which occur as each steam admission valve starts to open. The cost function is obtained based on the ripple curve for more accurate modeling. Thus the equation (2) can be modified using a sine function to model the ripples to valve point effect as

$$
\begin{aligned}
& F_{i}\left(P_{i}\right)=\sum_{m=1}^{M} \sum_{i=1}^{N}\left[\mathbf{a}_{\mathbf{i}} \mathbf{P}_{\mathbf{i} \mathbf{m}}{ }^{2}+\mathbf{b}_{\mathbf{i}} \mathbf{P}_{\mathbf{i} \mathbf{m}}+\mathbf{c}_{\mathbf{i}}\right. \\
& \left.\left.+\mid g_{i \sin \{} m_{i}\left(P_{i \min }-P_{i m}\right)\right\}\right] \quad \$ / h r
\end{aligned}
$$

Where

$\mathrm{g}_{\mathrm{i}}$ and $\mathrm{m}_{\mathrm{i}}$ are the valve point effect co-efficient of unit $\mathrm{i}$

\subsection{Emission Equation}

The Emission equation of a generating unit is usually described by a quadratic function of power output $\mathrm{P} i$ as:

$$
E_{i}\left(P_{i}\right)=\mathrm{d}_{\mathrm{i}} \mathrm{P}_{\mathrm{i}}^{2}+\mathrm{e}_{\mathrm{i}} \mathrm{P}_{\mathrm{i}}+\mathrm{f}_{\mathrm{i}} \quad \mathrm{Kg} / \mathrm{hr}
$$

Where

$\mathrm{d}_{\mathrm{i}}, \mathrm{e}_{\mathrm{i}}$ and $\mathrm{f}_{\mathrm{i}}$ are the emission co-efficient of unit $\mathrm{i}$

\subsection{Emission Constrained Cost Equation}

The Emission constrained cost equation can now be formulated as:

$$
F_{i}^{\mid}\left(P_{i}\right)=\left(\mathrm{a}_{\mathrm{i}} \mathrm{P}_{\mathrm{i}}{ }^{2}+\mathrm{b}_{\mathrm{i}} \mathrm{P}_{\mathrm{i}}+\mathrm{c}_{\mathrm{i}}\right)+\mathrm{h}_{\mathrm{i}}\left(\mathrm{d}_{\mathrm{i}} \mathrm{P}_{\mathrm{i}}{ }^{2}+\mathrm{e}_{\mathrm{i}} \mathrm{P}_{\mathrm{i}}+\mathrm{f}_{\mathrm{i}}\right) \$ / \mathrm{hr}(5)
$$

Where

$\mathrm{h}_{\mathrm{i}}=F_{i} \max / E_{i} \max$

$$
F_{i} \max =\mathrm{a}_{\mathrm{i}} \mathrm{P}_{\mathrm{i}}^{2} \max +\mathrm{b}_{\mathrm{i}} \mathrm{P}_{\mathrm{i}} \max +\mathrm{c}_{\mathrm{i}}
$$


$E_{i} \max =\mathrm{d}_{\mathrm{i}} \mathrm{P}_{\mathrm{i}}^{2} \max +\mathrm{e}_{\mathrm{i}} \mathrm{P}_{\mathrm{i}} \max +\mathrm{f}_{\mathrm{i}} \quad \mathrm{Kg} / \mathrm{hr}$

\subsection{Power Balance Constraints}

The total generation must supply the demand

$\Sigma\left(\mathrm{P}_{\mathrm{i}}\right)=\mathrm{P}_{\mathrm{D}}$

Where

$\mathrm{P}_{\mathrm{D}}$ is the load demand

\subsection{Generator Limit Constraints}

The power generation of unit ' $n$ ' should be between its minimum and maximum limits.

$$
\mathrm{P}_{\mathrm{n}} \min <\mathrm{P}_{\mathrm{n}}<\mathrm{P}_{\mathrm{n}} \max
$$

Where

$P_{i}$ min is the minimum generation limit of unit $i$ $P_{i}$ max is the maximum generation limit of unit $i$

\section{IMPROVED TABU SEARCH ALGORITHM}

An Improved Tabu Search (ITS) search is a higher-level method or strategy for solving optimization problems. The ITS approach can be imposed on any procedure whose operations produce a sequence of moves that lead from one trail solution to another. Each move is obtained from a set of available alternatives that are be evaluated by one or more functions that measure their attractiveness in some local sense. Applying to the optimization problems, the ITS starts at some initial solution and then moves to a neighboring solution. A neighboring solution is generated by a set of admissible moves. At each iteration the method moves to the best solution in the neighborhood of the current solution. The best solution of all stages is sorted as the new best solution and used as forward initial solution for every stage. Finally, the searching of all stages has completed their solutions, applying the global updating to select the best solution. The details of the ITS is applied to ED problem are given in the following Algorithm.

a. Set initial solution of stage $i$ to be current solution

b. $\quad \mathrm{S}^{\mathrm{i}} \mathrm{O}=\left(\mathrm{P}_{1} \mathrm{P}_{2} \ldots \ldots \ldots \mathrm{P}_{\mathrm{N}}\right)$ where $\mathrm{P}_{1} \mathrm{P}_{2} \ldots \ldots . . \mathrm{P}_{\mathrm{N}}=$ Output power of Generating unit

c. $\quad \mathrm{N}=$ Number of total generating unit in this system

d. Set, Iteration count $\mathrm{K}=0$

e. Tabu list as empty

f. Calculate the total fuel cost function of each stage $F_{T}$ $\left(\mathrm{S}_{\mathrm{O}}^{\mathrm{O}}\right)$

g. Set best solution $\left(\mathrm{S}_{\mathrm{b}}^{\mathrm{i}}\right)=$ current solution $\mathrm{S}_{\mathrm{O}}^{\mathrm{i}} \quad$ and $\mathrm{F}_{\mathrm{T}}$ $\left(\mathrm{S}_{\mathrm{O}}^{\mathrm{i}}\right)=\mathrm{F}_{\mathrm{T}}\left(\mathrm{S}_{\mathrm{b}}^{\mathrm{i}}\right)$

h. Find as set of neighbors solution $\mathrm{S}_{\text {neighbour }}^{\mathrm{i}}$ of $\left(\mathrm{S}_{\mathrm{b}}^{\mathrm{i}}\right)$

i. Calculate total fuel cost function $\mathrm{F}_{\mathrm{T}}\left(\mathrm{S}^{\mathrm{i}}\right.$ neighbour $)$

j. If $\mathrm{F}_{\mathrm{T}}\left(\mathrm{S}^{\mathrm{i}}\right.$ neighbour $)<\mathrm{F}_{\mathrm{T}}\left(\mathrm{S}_{\mathrm{b}}^{\mathrm{i}}\right)$, update solution

k. Set $\left(\mathrm{S}_{\mathrm{b}}^{\mathrm{i}}\right)=\left(\mathrm{S}^{\mathrm{i}}\right.$ neighbour$)$, else do not update solution

1. Update tabu list, i.e, regency frequency \& move direction are update

m. Check the condition of interchange solutions. If reaches the appropriate point, inter change solutions between stages; the best solution of all stages is sorted as the new best solution and used as forward initial solution for every stage. Set iteration counter $\mathrm{K}=\mathrm{K}+1$ and go to Step e n. Stop if the termination criterion is satisfied and global updating solution else go to step e

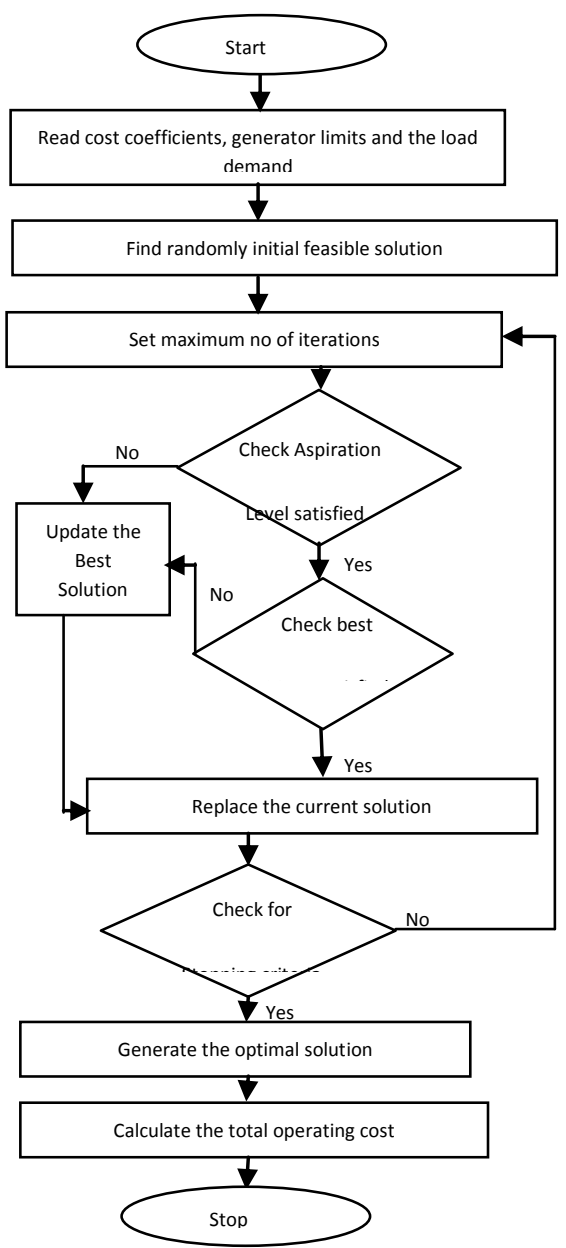

Fig 1 Flow chart for Improved Tabu search application to Economic load dispatch

\section{EXPIREMENTS AND RESULTS}

The power system economic dispatch problem based on the concept of Improved Tabu Search method has been tested on 3generator system, 6-generator system and 13-generator system. Multiple generator limits and total operating cost of the system is simulated in order to evaluate the correctness as well as accuracy of this method. The first test system consists of 3-generating units with various demand of 200-400 MW. The cost coefficient, emission coefficient and generating limits of the 3-generator system are shown in table (1).The second test system consists of 6-generating units with various demand of 500-1100 MW. The cost coefficient, emission coefficient and generating limits of the 6-generator system are shown in table (2).The third test system consists of 13-generating units with total demand of $2520 \mathrm{MW}$. The cost coefficient, valve point coefficient and generating limits of the 13-generator system are shown in table (3). 
Table 1.Cost Coefficients, Emission Coefficients and Power Limits of three Generator systems

\begin{tabular}{|c|c|c|c|c|c|c|c|c|}
\hline $\mathrm{G}$ & $\mathrm{a}_{\mathrm{i}}$ & $\mathrm{b}_{\mathrm{i}}$ & $\mathrm{c}_{\mathrm{i}}$ & $\mathrm{d}_{\mathrm{i}}$ & $\mathrm{e}_{\mathrm{i}}$ & $\mathrm{f}_{\mathrm{i}}$ & $\mathrm{P}_{\min }$ & $\mathrm{P}_{\max }$ \\
\hline 1 & 0.005 & 2.45 & 105 & 0.0126 & -1.355 & 22.983 & 20 & 200 \\
\hline 2 & 0.005 & 3.51 & 44.1 & 0.01375 & -1.249 & 137.370 & 15 & 150 \\
\hline 3 & 0.005 & 3.89 & 40.6 & 0.00765 & -0.805 & 363.704 & 18 & 180 \\
\hline
\end{tabular}

Table 2.Cost Coefficients, Emission Coefficients and Power Limits of Six Generator Systems

\begin{tabular}{|c|c|c|c|c|c|c|c|c|}
\hline $\mathrm{G}$ & $\mathrm{a}_{\mathrm{i}}$ & $\mathrm{b}_{\mathrm{i}}$ & $\mathrm{c}_{\mathrm{i}}$ & $\mathrm{d}_{\mathrm{i}}$ & $\mathrm{e}_{\mathrm{i}}$ & $\mathrm{f}_{\mathrm{i}}$ & $\begin{array}{c}\mathrm{P} \\
\min \end{array}$ & $\begin{array}{c}\mathrm{P} \\
\max \end{array}$ \\
\hline 1 & 0.152 & 38.540 & 756.80 & 0.0042 & 0.3300 & 13.86 & 10 & 125 \\
\hline 2 & 0.106 & 46.160 & 451.32 & 0.0042 & 0.3300 & 13.86 & 10 & 150 \\
\hline 3 & 0.028 & 40.400 & 1050.00 & 0.0068 & -0.5455 & 40.26 & 35 & 225 \\
\hline 4 & 0.035 & 38.310 & 1243.53 & 0.0068 & -0.5455 & 40.26 & 35 & 210 \\
\hline 5 & 0.021 & 36.328 & 1658.57 & 0.0046 & -0.5112 & 42.92 & 130 & 325 \\
\hline 6 & 0.018 & 38.270 & 1356.66 & 0.0046 & -0.5112 & 42.96 & 125 & 315 \\
\hline
\end{tabular}

Table3.Cost Coefficients, Valve Point Effect Coefficients and Power Limits of Thirteen Generator System

\begin{tabular}{|c|c|c|c|c|c|c|}
\hline$P_{i \min }$ & $\mathrm{P}_{\mathrm{imax}}$ & $a_{i}$ & $b_{i}$ & $c_{i}$ & $g_{i}$ & $\mathrm{~m}_{\mathrm{i}}$ \\
\hline 0 & 680 & 550 & 8.1 & 0.00028 & 300 & 0.035 \\
\hline 0 & 360 & 309 & 8.1 & 0.00056 & 200 & 0.042 \\
\hline 0 & 360 & 307 & 8.1 & 0.00056 & 200 & 0.042 \\
\hline 60 & 200 & 240 & 7.74 & 0.00324 & 150 & 0.063 \\
\hline 60 & 200 & 240 & 7.74 & 0.00324 & 150 & 0.063 \\
\hline 60 & 200 & 240 & 7.74 & 0.00324 & 150 & 0.063 \\
\hline 60 & 200 & 240 & 7.74 & 0.00324 & 150 & 0.063 \\
\hline 60 & 200 & 240 & 7.74 & 0.00324 & 150 & 0.063 \\
\hline 60 & 200 & 240 & 7.74 & 0.00324 & 150 & 0.063 \\
\hline 40 & 120 & 126 & 8.6 & 0.00284 & 100 & 0.084 \\
\hline 40 & 120 & 126 & 8.6 & 0.00284 & 100 & 0.084 \\
\hline 55 & 120 & 126 & 8.6 & 0.00284 & 100 & 0.084 \\
\hline 55 & 120 & 126 & 8.6 & 0.00284 & 100 & 0.084 \\
\hline
\end{tabular}

\section{SIMULATION TEST RESULTS}

The Improved Tabu Search Algorithm is used to solve the Economic Dispatch problem for 3-generator test system, 6generator test system and 13-generator test system. The simulation is carried out using c++ software. The total operating cost and emission level of system is minimized. The computational results of table 4 and table 5 consists of three generator test system and six generator test system respectively, shows that ITS fuel cost functions value and emission level is less than conventional methods. The computational results of table 6 consist of thirteen generator test system. It shows that ITS fuel cost function with valve point effect loading is less than HNN, GA, TSA and DTSA. The test system data produce the better result for 3-generating units, 6-generating units and 13-generating units. It concludes that the total fuel cost and emission level is minimum in Improved Tabu Search Algorithm compared to other techniques with considering fuel cost functions, valve point effect functions, emission equations, emission constrained cost equation, power balance constraints and generator limit constraints. In comparison of the test system, it can be seen that when a large scale problem, ITS can clearly obtain solution better than other methods and converges to near global minimum with less search account.

Table 4.Comparison of Improved Tabu Search Solution of Economic Dispatch Cost and Emission under Various Load Conditions for Three Generator System

\begin{tabular}{|c|c|c|c|c|}
\hline \multirow{2}{*}{$\begin{array}{c}\text { Generation } \\
\text { MW }\end{array}$} & \multicolumn{2}{|c|}{ Total Cost $(\$ / \mathrm{hr})$} & \multicolumn{2}{c|}{ Total Emission $(\mathrm{Kg} / \mathrm{hr})$} \\
\cline { 2 - 5 } & $\begin{array}{c}\text { Proposed } \\
\text { Method }\end{array}$ & $\begin{array}{c}\text { Conventional } \\
\text { Method }\end{array}$ & $\begin{array}{c}\text { Proposed } \\
\text { Method }\end{array}$ & $\begin{array}{c}\text { Conventional } \\
\text { Method }\end{array}$ \\
\hline 200 & $\mathbf{8 5 6 . 1 0 5 2}$ & 886.234 & $\mathbf{5 2 1 . 0 8 1 5}$ & 529.26 \\
\hline 250 & $\mathbf{1 0 5 5 . 1 6 5 7}$ & 1096.68 & $\mathbf{5 8 3 . 7 9 4 2}$ & 597.499 \\
\hline 300 & $\mathbf{1 3 1 2 . 3 8 0 1}$ & 1318.15 & $\mathbf{6 7 9 . 6 3 7 8}$ & 684.826 \\
\hline 350 & $\mathbf{1 4 8 3 . 3 3 2 3}$ & 1550.64 & $\mathbf{7 6 2 . 1 8 7 8}$ & 791.24 \\
\hline 400 & $\mathbf{1 7 1 2 . 2 4 3 7}$ & 1794.17 & $\mathbf{8 7 8 . 5 7 6 5}$ & 916.742 \\
\hline
\end{tabular}

Table 5.Comparison of Improved Tabu Search Solution of Economic Dispatch Cost and Emission under various load conditions for six generator system

\begin{tabular}{|c|c|c|c|c|}
\hline \multirow{2}{*}{$\begin{array}{c}\text { Generation } \\
\text { MW }\end{array}$} & \multicolumn{2}{|c|}{ Total Cost $(\$ / \mathrm{hr})$} & \multicolumn{2}{c|}{ Total Emission (Kg/hr) } \\
\cline { 2 - 5 } & $\begin{array}{c}\text { Proposed } \\
\text { Method }\end{array}$ & $\begin{array}{c}\text { Conventional } \\
\text { Method }\end{array}$ & $\begin{array}{c}\text { Proposed } \\
\text { Method }\end{array}$ & $\begin{array}{c}\text { Conventional } \\
\text { Method }\end{array}$ \\
\hline 500 & $\mathbf{2 6 9 9 2 . 7 1 6 3}$ & 27092.5 & $\mathbf{2 5 1 . 1 8 2 2}$ & 261.634 \\
\hline 600 & $\mathbf{3 1 4 2 9 . 3 0 6 4}$ & 31628.68 & $\mathbf{3 2 9 . 3 5 9 9}$ & 338.992 \\
\hline 700 & $\mathbf{3 6 2 8 2 . 4 1 6 1}$ & 36313.9 & $\mathbf{4 2 8 . 5 0 9 5}$ & 434.38 \\
\hline
\end{tabular}




\begin{tabular}{|c|c|c|c|c|}
\hline 800 & $\mathbf{4 0 7 3 1 . 4 0 0 0}$ & 41148.3 & $\mathbf{5 4 0 . 2 8 0 1}$ & 547.796 \\
\hline 900 & $\mathbf{4 5 4 5 0 . 4 1 8 9}$ & 46131.8 & $\mathbf{6 5 0 . 4 2 4 0}$ & 679.24 \\
\hline 1000 & $\mathbf{5 0 4 3 3 . 1 0 4 6}$ & 51264.5 & $\mathbf{7 9 3 . 7 6 4 0}$ & 828.72 \\
\hline 1100 & $\mathbf{5 5 4 4 8 . 1 4 2 0}$ & 56546.2 & $\mathbf{9 5 3 . 3 3 1 1}$ & 996.224 \\
\hline
\end{tabular}

Table 6.Comparison of Improved Tabu Search Solution of Economic Dispatch with valve point effect loading for thirteen generator test system of $P D=2520 \mathrm{MW}$

\begin{tabular}{|c|c|c|c|c|}
\hline $\begin{array}{c}\text { Power } \\
\text { MW }\end{array}$ & GA & TSA & DTSA & ITS \\
\hline$P_{1}$ & 628.32 & 628.317 & 628.3182 & 635.281229 \\
\hline$P_{2}$ & 356.80 & 299.206 & 299.1962 & 344.786095 \\
\hline$P_{3}$ & 359.45 & 331.991 & 299.1950 & 304.906053 \\
\hline $\mathrm{P}_{4}$ & 159.73 & 159.733 & 159.7310 & 174.286064 \\
\hline$P_{5}$ & 109.86 & 159.711 & 159.7310 & 154.707142 \\
\hline$P_{6}$ & 159.73 & 159.744 & 159.7322 & 123.363731 \\
\hline$P_{7}$ & 159.73 & 159.739 & 159.7330 & 192.027052 \\
\hline$P_{8}$ & 159.73 & 159.742 & 159.7320 & 110.579595 \\
\hline$P_{9}$ & 159.73 & 159.700 & 159.7280 & 196.31128 \\
\hline$P_{10}$ & 76.92 & 40.009 & 77.3974 & 83.846013 \\
\hline$P_{11}$ & 75 & 77.720 & 77.3974 & 56.524879 \\
\hline$P_{12}$ & 60 & 92.348 & 92.3974 & 80.556032 \\
\hline$P_{13}$ & 55.00 & 92.335 & 87.7111 & 62.91067 \\
\hline $\mathrm{P}_{\mathrm{T}}$ & 2520.000 & 2520.000 & 2520.000 & 2520.000 \\
\hline $\begin{array}{c}\text { Total } \\
\text { Fuel } \\
\text { Cost } \\
(\$ / \mathrm{hr})\end{array}$ & 24400 & 24314.755 & 24169.956 & 24080.5523 \\
\hline
\end{tabular}

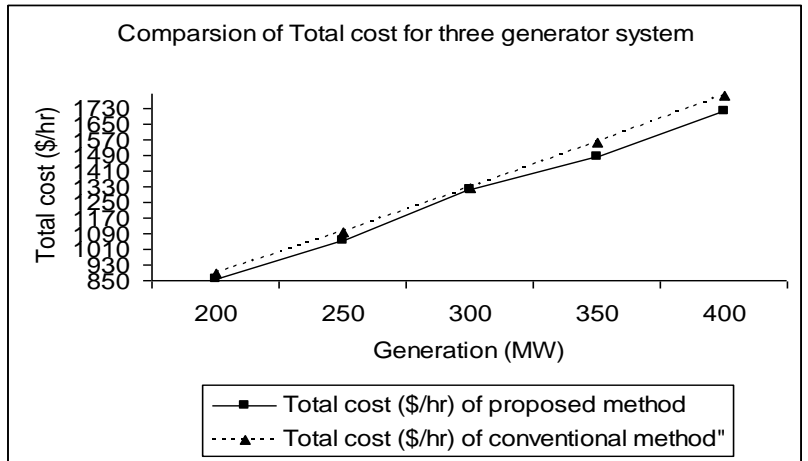

Fig 2 comparison of Total cost of three generator system

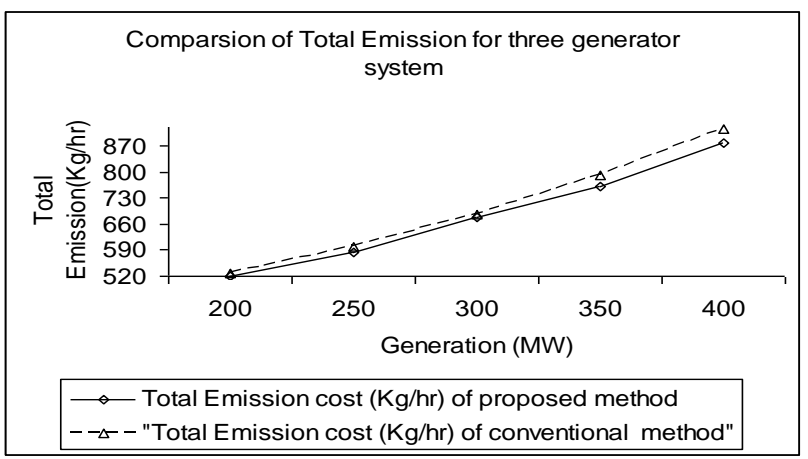

Fig 3 comparison of Total Emission of three generator system

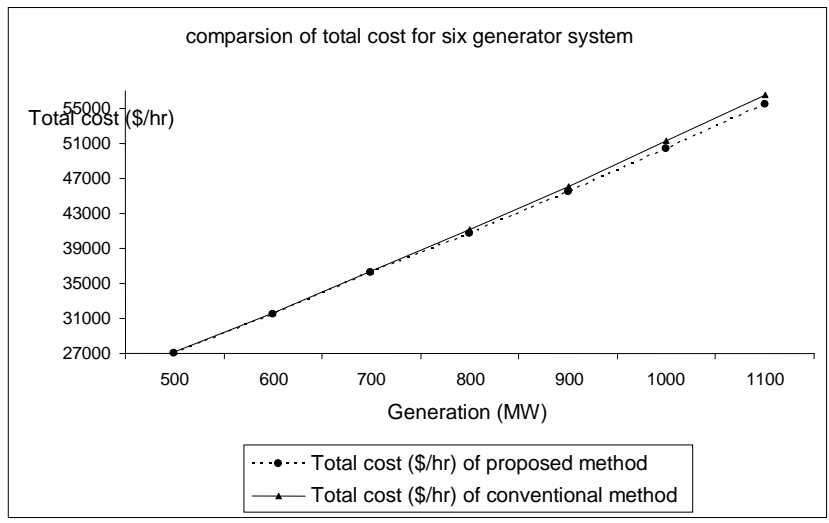

Fig 4 comparison of Total Emission of six generator system 


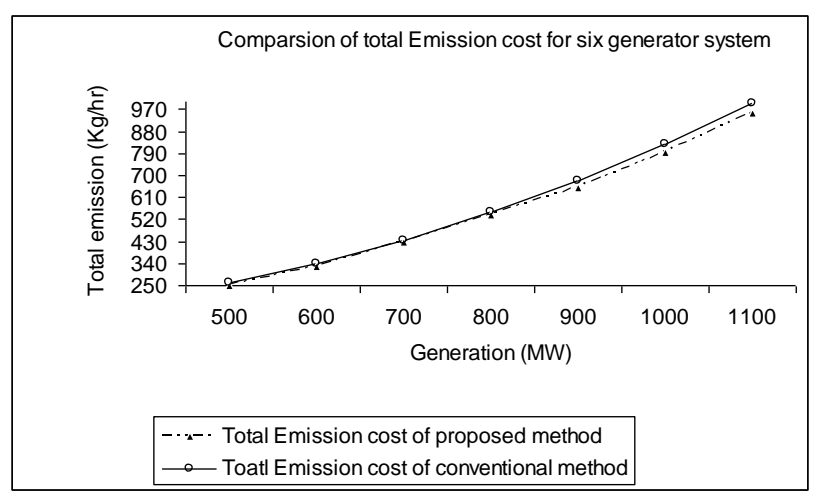

\section{Fig 5 comparison of Total Emission cost for six generator system}

\section{SUMMARY AND CONCLUSION}

The salient feature of this technique is that all the former conventional procedures have been avoided completely. This method has boundless applications for economic generation studies with different constraints. An accurate solution is available on comparison with other conventional results. The validity of the proposed method is demonstrated with the help of three standard test systems. The Emission Constrained Economic Dispatch (ECED) provides lower cost with a curb in emission. This property is revealed in table (IV \& V) for various load conditions. The computational results of table (VI) consist of thirteen generator test system. It shows that ITS fuel cost function with valve point effect loading is less than HNN, GA, TSA and DTSA. Comparisons of total cost and total emission under Emission Constrained Economic Dispatch (ECED) condition with that of cost minimum and emission minimum situations are graphically presented in figure (2-5). It involves a detailed comparative study for the best optimum configuration. The claims of some of the recent reports provide near optimal solution for large computationally intensive problem. Many of the hybrid algorithms only help to improve the solution accuracy. But this proposed algorithm is very well defined and the solution accuracy is excellent is conformity with the conventional techniques. The results show that Improved Tabu search Algorithm (ITSA) can converges to near global minimum with less search account. It is high efficiency than other methods. Thus, it obtains the solution with high accuracy.An Improved Tabu search algorithm has been developed for the economic thermal power dispatch problem of electric generating units. The algorithm was implemented and tested on 3-generator test system, 6-generator test system and 13generator test system.Improved Tabu Search Algorithm is an efficient tool for the economic scheduling for generating units with the given generator constraints and other data. The quality of the solution shows that an improved Tabu Search offers a promising viable approach for solves the economic thermal power dispatch problem. The solution is analytic in nature with high accuracy involving less computational time. Its use for any online application becomes boundless. The numerical results have shown the performance and applicability of the proposed method.

\section{ACKNOWLEDGMENTS}

The authors gratefully acknowledge the authorities of St.Joseph college of Engineering and Technology, Dar Es Salaam, Tanzania for the facilities offered to carry out this work.

\section{REFERENCES}

[1] K. P. Wong and J. Yuryevich, "Evolutionary- programmingbased algorithm for environmentally-constrained economic dispatch," IEEE Trans. Power System., vol. 13, pp. 301-306, May 1998.

[2] J. H. Park, K. Y. Lee and A. S. Yome, "Adaptive Hopfield Networks for economic load dispatch," IEEE Trans. Power System., vol. 13, pp. 519-526, May 1998.

[3] Liladhur G. Sewothul, Robert T.F. Ah King and Harry C.S.Rughooputh, "Genetic algorithms for economic dispatch with valve point effect", Proceedings of the IEEE, International conference on Networking, Sensing \& Control, pp.1358-1362, March 2004.

[4] M. Basu, "An interactive fuzzy satisfying-based simulated annealing techniques for economic emission load dispatch with nonsmooth fuel cost and emission level functions", Electric Power Components and Systems, vol.32, no.2, pp.163-173, 2004.

[5] S.Khamsawang, S.Pothiya and C.Booseng, "Distributed Tabu Search for solving the economic dispatch problem", IEEE Trans. Power System., vol. 20, pp. 484-487, 2004.

[6] M. Basu, "Particle Swarm Optimization based goalattainment method for dynamic economic emission dispatch", Electric Power Components and Systems, vol.34, pp.1015-1025, 2006.

[7] S.Muralidharan, K.Srikrishna and S. Subramanian, "Emission constrained economic dispatch- A new recursive approach", Electric Power Components and Systems, vol.34, no.3, pp.343-353, 2006.

[8] Whei-Min Lin, Fu-Sheng Cheng and Min-Tong Tsay, "An Improved Tabu Search for Economic Dispatch with Multiple Minima", IEEE Trans. Power System. vol. 17, No.1, pp. 108112, Feb 2002

\section{BIOGRAPHY}

K.Senthil received the Master of Engineering in Power Systems from the Faculty of Engineering \& Technology, Annamalai University, Chidambaram, India in 2008. Currently, he is a Lecturer of Electrical \& Electronics Engineering Department, St.Joseph College of Engineering \& Technology, Dar Es Salaam, Tanzania. He was a Lecturer in the Department of Electrical \& Electronics Engineering, at Lord Venkateshwaraa Engineering College, Puliambakkam, Kanchipuram, India and E.S.College of Engineering \& Technology, Villupuram, India from 2007 to 2008. $\mathrm{He}$ is an author of three international journals \& four Conference papers. His areas of research include Economic Dispatch, Emission Dispatch and Power system optimization. $\mathrm{He}$ is a member of Institution of Engineers India (IEI), Member of Indian society for technical education (MISTE), Member of Engineers Registration Board (ERB), Dar Es Salaam, Tanzania and Member of Ecological Society of Eastern Africa (ESEA), Kenya. 